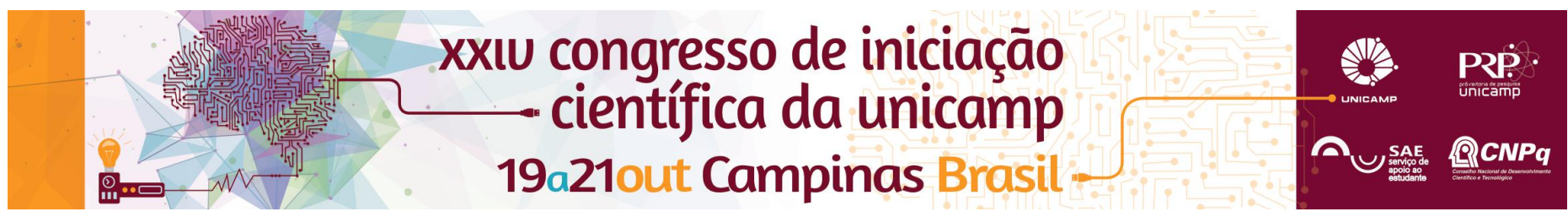

\title{
Caracterização de Fotomultiplicadores de Silício em Argônio Líquido para o futuro experimento DUNE (LBNE)
}

\section{Yago P Porto Silva, Ettore Segreto}

\begin{abstract}
Resumo
A Física de neutrinos vive um momento de intensa expectativa. Podem sair do estudo destas partículas únicas, as respostas para questões profundas sobre o Universo. Por isso, vários experimentos baseados na revelação da luz liberada na interação entre neutrinos e argônio líquido (LAr) vêm sendo propostos, do qual um exemplo é o DUNE (Deep Underground Neutrino Experiment). Para a detecção luminosa, ganham força os fotomultiplicadores de silício (SiPM). Este trabalho visou o estudo e desenvolvimento da eletrônica de leitura dos sinais elétricos de detecção do SiPM.
\end{abstract}

\section{Palavras-chave:}

Neutrinos, fotomultiplicadores de silício, argônio líquido

\section{Introdução}

O primeiro a propor a existência do neutrino foi Pauli em 1930. Desde então, esta estranha partícula passou a protagonizar os maiores mistérios da Física: oscilações quânticas [1], violação de simetrias que podem explicar a desigualdade entre matéria e antimatéria, equivalência (ou não) entre o neutrino e sua antipartícula, forte candidato a compor matéria escura [2].

Apesar de sua abundância no Universo, o fato de só interagirem via força fraca e possuírem massa muito pequena faz com que apenas experimentos com grande massa ativa, como o DUNE [3], sejam projetados para para elucidar estas questões em aberto.

O objetivo deste projeto foi a realização de um sistema de testes e leitura do SiPM para conferir propriedades como ganho, eficiência, pulsos secundários e corrente de escuro. Este sistema é composto de caixa de isolação luminosa (ou caixa escura), pulsadores de LED, atenuador para a alimentaçãoo elétrica e amplificador de sinal.

\section{Resultados e Discussão}

Os itens desenvolvidos para os testes com os SiPMs:

1) Caixa escura: isola a fotomultiplicadora da maior parte da luz ambiente;

2) Circuitos pulsadores: foram construídos dois circuitos para fazer um LED piscar numa frequência precisa. O LED era a principal excitação luminosa dos fotomultiplicadores;

3) Atenuador: o laboratório possuía apenas fontes de alta tensão (centenas ou milhares de Volts), instáveis para fornecer tensões na faixa de 70 Volts, necessária para a alimentação do SiPM. A solução foi a construção de um circuito que abaixasse a tensão de 600 para 70 Volts de forma confiável;

4) Leitura do sinal: os esquemas são mostrados na figura 1, a primeira alternativa usa 4 trasistores MOS conectados ao chip, a segunda liga todas as células à um único amplificador operacional;

5) Circuito de simulação do pulso de detecção e amplificador: para teste de um amplificador de sinal foi desenvolvido um circuito simples para gerar pulsos similares aos de detecção do SiPM.
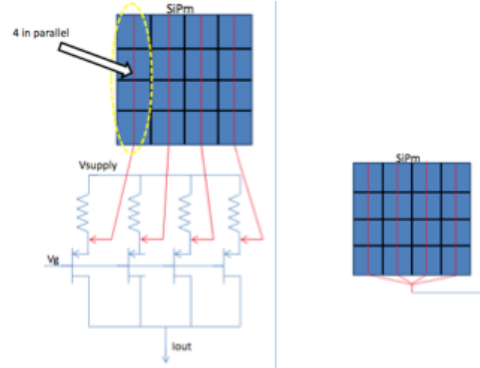

Figura 1. Esquemas para a leitura de sinal do SiPM.

\section{Conclusões}

Dados sobre o comportamento do SiPM foram coletados com sucesso, com destaque para o teste integrado ao ARAPUCA [4], do qual os dados para contruir o sinal abaixo foram tomados .

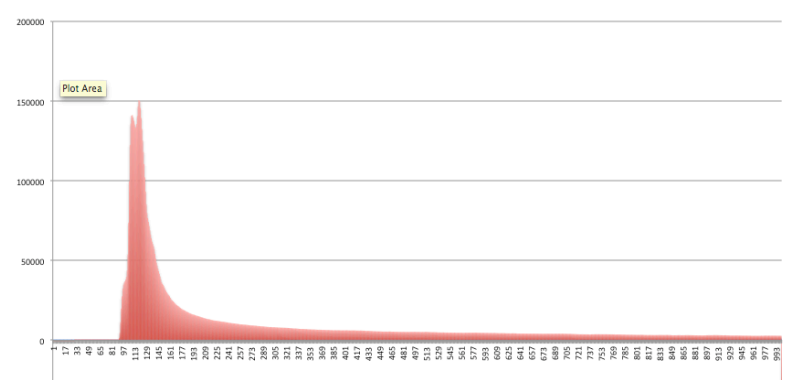

Figura 2. Sinal de fotodeteção.

\section{Agradecimentos}

Instituições de fomento bolsa PIBIC: CNPq e SAE.

[1] Kamiokande collaboration, Phys. Lett. B205 (1988) 416, Phys. Lett. B335 (1994) 237

Macro collaboration, Phys. Lett. B357 (1995) 481

SuperKamiokande collaboration, Phys. Rev. Lett. 81 (1998) 1562;

[2] LSND collaboration, Phys. Rev. Lett. 81 (1998) 1774;

[3] LBNE Conceptual Design Report (6 volumes), March 2012,http://lbne2 docdb.fnal.gov:8080/0052/005235/005/volume-1-LAr.pdf;

[4] Machado, A.A., Segreto, E.; ARAPUCA a new device for liquid argon scintillation light detection, Journal of Instrumentation, Vol. 11, Feb. 2016 